\title{
Physical, chemical, and nutritional quality parameters of three different types of oil: determination of their reusability in deep frying
}

\author{
${ }^{1}$ Habarakada, A., ${ }^{1, *}$ Perumpuli, P.A.B.N., ${ }^{1}$ Thathsaranee, W.T.V. and ${ }^{2}$ Wanninaika, I.P. \\ ${ }^{1}$ Department of Food Science and Technology, Faculty of Agriculture, University of Ruhuna, Mapalana, \\ Kamburupitiya, Sri Lanka. \\ ${ }^{2}$ Department of Chemistry, Faculty of Science, University of Colombo, Colombo, Sri Lanka.
}

\begin{abstract}
Article history:
Received: 31 January 2021

Received in revised form: 8

March 2021

Accepted: 21 April 2021

Available Online: 19 October 2021
\end{abstract}

Keywords:

Edible oil,

Nutritional quality,

Physicochemical parameters,

Repeated frying,

Reusability

\section{DOI:}

https://doi.org/10.26656/fr.2017.5(5).079

\begin{abstract}
Deep frying is the process of immersing food in hot oil at a temperature of approximately $180^{\circ} \mathrm{C}$. During deep frying, different chemical reactions are taking place, resulting in changes in the physicochemical properties of the frying oil, eventually leading to harmful health effects on the consumers. Nevertheless, based on economic feasibility, both the domestic and industrial levels tend to repeatedly use edible oils for deep frying. Thus, the current study aimed to evaluate physicochemical and nutritional parameters of commercially available coconut oil, palm oil and sunflower oil and to investigate the effect of repeated deep frying for the physicochemical and nutritional parameters of the studied oil samples. Thereby, the optimum number of frying cycles for each type of oil was also investigated. In order to achieve that, using coconut, palm and sunflower oils, potato and fish were fried separately for five repeated frying cycles. As per the results, regardless of the frying material, the relative density, colour, peroxide value, free fatty acid value of coconut oil, palm oil, and sunflower oil were increased significantly with increase the number of frying cycles whereas the smoke point and moisture content was found to be significantly decreased. In contrast, the number of cycles suitable for repeated frying is varying upon the frying material. Accordingly, coconut oil has proven to be used for three frying cycles of potato and five frying cycles of fish: palm oil for one frying of potato and two fryings of fish without adversely altering their physicochemical and nutritional properties. Conferring to the obtained results, the use of unsaturated oil like sunflower oil on repeated frying is not recommended.
\end{abstract}

\section{Introduction}

Deep frying is one of the utmost methods used in food preparation wherein edible vegetable oil is considered the foremost constituent in its frying process. Deep-fried food materials are immersed in hot oil at high temperatures approximately at $180^{\circ} \mathrm{C}$. Heating the oil into such high temperatures causes hydrolysis, oxidation and polymerization reactions that lead to change in the composition of the oil which in turn change its flavour and stability. Furthermore, the viscosity, darkness and foaming ability of the edible oil is supposed to be increased with each repeated frying cycle whereas the smoke point is known to be decreased. During frying, oil is decomposing into different types of volatile compounds and monomeric and polymeric products that contribute not only to the adverse sensory and nutritional qualities but also to the reduced shelf life of the fried products. However, deep-frying under proper conditions might result in some favourable compounds which are accountable for the agreeable flavour, taste, crispy texture, and the characteristic golden colour of the fried food materials. However, most commonly the free radicals, trans-fatty acids, conjugated linoleic acids, and some oxidized volatile products formed during deep frying are known to be answerable for the off flavour, reduction of the shelf life of the edible oil while causing adverse health issues for its consumers (Alzaa et al., 2018).

As it was reported by Saxena (2104), the recurrent use of cooking oil in frying has caused a considerable increment of the trans fatty acid content in the frying oil which would eventually act as saturated fatty acids within the human body. In addition, this oil consumption pattern has also resulted in an increment of the total serum level and low-density lipoprotein levels (GarridoPolonio et al.,2009). Moreover, the presence of polar 
compounds in repeatedly fried oil has been accompanied by an increased health risk of developing hypertension (Lapointe et al., 2006). Furthermore, reusing frying oil leads to harmful health risks such as cell deviations (Leong et al., 2008) and modifications in genetic material(Sülzle et al., 2004). Moreover, free radicals produced during frying will leads to oxidative stress through lipid peroxidation.

Nevertheless, in the fast-moving society, the consumption pattern of deep-fried, ready-made food among the people in developing countries are everincreasing. Edible vegetable oils such as coconut oil, palm oil and sunflower oil are often being used as major constituents for deep frying at both the domestic and industrial levels. The cost of oil has become one of the major factors affecting economic feasibility. Therefore, regardless of the harmful impacts on the health state of the consumers, these edible oils are often being used for repeated deep frying. However, little is known about the optimum utilization times for deep-fried cooking oil which would cause less harmful effects on human health. Therefore, this research study has been conducted with the aim of evaluating the reusability of coconut oil, palm oil and sunflower oil with special reference to their effect of physicochemical and nutritional properties upon the repeated deep frying. Thereby, the optimum number of deep-frying cycles for both carbohydrate-rich fried food (potato) and protein-rich fried food (fish) to minimize the health hazards has also being investigated.

\section{Materials and methods}

\subsection{Preparation of frying material}

Fresh salaya fish (Sardinella gibbosa) purchased from the local fish market were eviscerated, descaled, and washed in running tap water, and stored at $-18^{\circ} \mathrm{C}$ until the experiment was conducted. They were thawed under normal room temperature before being used for frying. Similarly, potato (Solanum tuberosum) was also purchased from the local market and were washed, peeled, and cut into chips with a thickness of two millimetres and a length of approximately one inch.

\subsection{Deep frying of food}

The volume of three litres of coconut oil, palm oil and sunflower oil were poured into the three separate frying pans. During the deep-frying process, prior to adding the frying material, each oil type was heated up to their smoke point and the smoke points temperatures were recorded separately. Five hundred grams of potato and five hundred grams of salaya were deep-fried separated in each type of oil. For each oil type, frying was repeated for five consecutive frying cycles using 500 $\mathrm{g}$ of potato and salaya separately in each frying cycle. At the beginning of each cycle, the used oil was filtered using a normal kitchen strainer. No topping up of oil was done throughout the frying process. Approximately 200 $\mathrm{mL}$ of each fresh oil sample (before starting the frying cycles) and $200 \mathrm{~mL}$ of used oil samples at the end of each frying cycle were also taken into separately labelled bottles for further analysis.

\subsection{Analysis of physicochemical parameters of oil}

\subsubsection{Determination of moisture content}

The moisture content of fresh oil and used oil (coconut oil, palm oil and sunflower oil) from each frying cycle of salaya and potato were determined using the standard oven-dry method (AOAC, 2000).

\subsubsection{Determination of relative density}

Determination of the relative density of each oil sample was conducted using a $50 \mathrm{~mL}$ relative density bottle. Firstly, the density bottle was cleaned, dried and the empty weight of the density bottle was taken. Then, the weight of the density bottle with water was recorded, and the bottles were emptied and dried completely to remove any water inside the bottles. Finally, the weight of the density bottle filled with each oil type (along with the stopper) was recorded. Each experiment was repeated three times.

\subsubsection{Determination of colour}

The colour of fresh and used coconut, palm and sunflower oils were examined using the Lovibond colourimeter (Lovibond, MR200, China), The L, a, b, and $h$ values for each oil samples were noted. The total colour change $(\Delta \mathrm{E})$ of each oil sample was calculated using the following equation.

\section{$\Delta \mathrm{E}=\sqrt{\left.L 2 *-L 1)^{2}+a 2 *-a 1 *\right)^{2}+(b 2 *-b 1)^{2}}$ \\ 2.3.4 Determination of free fatty acid value}

Approximately $25 \mathrm{~mL}$ of an equal mixture of ethyl alcohol and ether was prepared. The oil sample (5 g) was weighed accurately into the dried conical flask, and 25 $\mathrm{mL}$ of 1:1 mixture of alcohol was added into the conical flask. The mixture was heated in a water bath until the oil was dissolved. The hot solution was titrated with potassium hydroxide $(\mathrm{KOH})$, using phenolphthalein as the indicator until the faint pink colour persists for a minute at the endpoint. The experiment was carried out in triplicate and a blank test was done without adding oil. Finally, the Acid Value was calculated by using Equation 2.

Acid Value $=\frac{\text { volume of titrant } \times \text { Normality of } \mathrm{KOH}(\mathrm{N}) \times 56.1}{\text { Mass of the }}$

\subsubsection{Determination of peroxide value of oil}

In order to determine the peroxide value (PV), $2 \mathrm{~g}$ of 
oil sample was weighed. Then $15 \mathrm{~mL}$ of glacial acetic acid, $10 \mathrm{~mL}$ of chloroform and $1 \mathrm{~mL}$ of saturated $\mathrm{KI}$ solution were added into the conical flask with weighed oil. The mixture was shaken well until brown and it was kept in a dark place for five mins. After the 5 mins period, $75 \mathrm{~mL}$ of distilled water and $2 \mathrm{~mL}$ of starch solution were added to the mixture. Then the mixture was titrated with $0.01 \mathrm{M} \mathrm{Na}_{2} \mathrm{~S}_{2} \mathrm{O}_{3}$ until the dark blue colour solution changes to a colourless solution. The experiment was carried out in triplicate. The peroxide value for each tested oil sample was determined using Equation 3.

Peroxide Value $=\frac{(\mathrm{vs}-\mathrm{vb}) \times \mathrm{N} \times 1000}{\mathrm{w}}$

\subsubsection{Determination of total antioxidant activity by DPPH assay method}

One millilitre of each sample of the series was taken into separate test tubes. Then, $3 \mathrm{~mL}$ of DPPH solution were added to that. Finally, that solution was volume up to $10 \mathrm{~mL}$ with $99 \%$ methanol. Samples were kept in a dark place for 30 mins. After 30 mins, the absorbance readings of each sample were recorded at $517 \mathrm{~nm}$ against blank using a UV visible spectrophotometer $(\mathrm{HACH}$, DR3900, Germany). All the tests were done in triplicate, and the DPPH radical scavenging activity percentage was calculated.

\subsubsection{Determination of total phenolic content}

Approximately $400 \mu \mathrm{L}$ of the sample or standard solution were taken into separate test tubes, and $2 \mathrm{~mL}$ of Folin-ciocalteu reagent was added to each sample. After 7 mins, $2 \mathrm{~mL}$ of $7.5 \% \mathrm{Na}_{2} \mathrm{CO}_{3}$ was added to each mixture, and volumed up to $10 \mathrm{~mL}$ by adding distilled water. Samples were incubated in a dark place for $2 \mathrm{hrs}$. Finally, the absorbance was taken at $760 \mathrm{~nm}$ using a UV visible spectrophotometer (HACH, DR3900, Germany). The standard curve was built up using seven different concentrations of gallic acid $(0.007813,0.015625$, $0.03125,0.0625,0.125,0.25$ and $0.5 \mathrm{mg} / \mathrm{mL}$ ). The total phenolic content was calculated as the gallic acid equivalent for samples, and the results were expressed as $\mathrm{mg}$ gallic acid equivalents per gram of extract.

\subsection{Statistical analysis}

The results obtained from the study were statistically analysed using Minitab with a significance level of 5\%.

\section{Results and discussion}

\subsection{Change in the smoke point}

The smoke point is the temperature at which the oil stops glistening and starts to burn and emits bluish smoke (AOAC, 2000). During this temperature, the fat in the oil starts to break down into glycerol and fatty acids, and the formed glycerol will be further broken into acrolein, which is one of the main compounds of bluish smokes (Wang, 2002). Moreover, these compounds are adversely affecting the odour and taste of fried food products.

The smoke point of coconut oil, palm oil and sunflower oil used for frying potato and salaya for five consecutive frying cycles were shown in Figure $1 \mathrm{~A}$ and Figure 1B respectively.

According to Hashem et al. (2017), the smoke point of an oil is greatly relying on the chain length of the fatty acids available in the oil where; oils rich in short-chain fatty acids are having a lower smoke point than oils with longer chain fatty acids. Furthermore, the smoke point is also determined by the content of the free fatty acids and to a lesser degree on partial glyceride (Alzaa et al., 2018). It is also considered an important measurement of any oil that is used for frying. The smoke point is inversely proportional to the free fatty acid content of the oil. Higher the free fatty acid content, lower the smoke point of the oil due to the higher tendency of fatty acids to be broken into products that emit smoke. Based on the literature, the initial smoke point of coconut oil, palm oil and sunflower oil is $177^{\circ} \mathrm{C}, 180^{\circ} \mathrm{C}$, and $225^{\circ} \mathrm{C}$ respectively(Eyers, 2015). According to the results of the current study, the smoke point of used coconut oil, palm oil and sunflower oil were found to be $183.2 \pm 2.5^{\circ}$ C, $193.2 \pm 12^{\circ} \mathrm{C}$, and $176 \pm 0.8^{\circ} \mathrm{C}$ respectively. These results are also in accordance with past work except for the smoke point values for sunflower oil. Oils like coconut oil and palm oil that are rich in lauric acid are having the lowest smoking point due to the presence of more volatile medium-chain and short-chain fatty acids. A higher smoke point is an important factor in frying oils since it specifies prolong the usage of frying oils. Furthermore, as it is shown in Figure 1A and Figure 1B, the smoke point of all the tested oils started to reduce with repeated frying cycles where the rate of reduction is much higher when frying fish. During deep frying, the fat in the oil is started to break into free fatty acids and glycerol, and the higher the content of fatty acids in the oil, the lower the smoke point of the oil. Thus, when reusing the same oil, the liberated free fatty acids are already existing in the oil, which leads to reduce the smoke point with an increase in the frying cycles. Moreover, it was observed that the type of frying material has an impact on altering the smoke point. The results of the present study revealed the fact that the deep -fried fish has caused a comparably higher rate of reduction in the smoke point (Figure 1A). This might be due to the addition of more water to the frying oil which attribute to accelerate the lipolysis process that releases a higher amount of free fatty acids. 
A

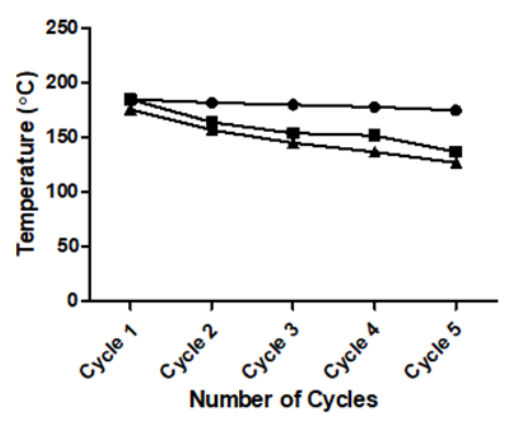

B

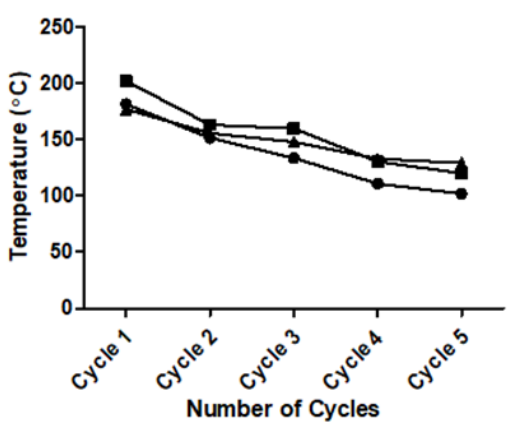

Figure 1. Variation of the smoke point $\left({ }^{\circ} \mathrm{C}\right)$ of coconut oil (Circles), palm oil (Squares) and sunflower oil (Triangles) with repeated frying of potato (A) and fish (B).

\subsection{Change in the moisture content during repeated frying}

The change of moisture content of coconut oil, palm oil and sunflower oil with repeated fried potato and fish were shown in Table 1.

As per the results, moisture content was decreased with the frequency of repeated frying for all three oil types. There was a significant difference $(p<0.05)$ in the moisture content of fresh oil samples and that of the fried oil sample at each frying frequency. The reduction in moisture content in oil with the frying frequency might have been resulted due to the evaporation of moisture from the food and oil to the atmosphere during the heat transfer process. The results reveal that the initial moisture content of the coconut oil, palm oil and sunflower oil is different due to their different processing methods. This might be due to the timing of frying and type of fryer; results do not tend to exhibit a unique reducing pattern in the type of food and that of oil.

\subsection{Effect of repeated use of oil in deep frying on their relative density}

In order to examine the effect of reuse of coconut, palm and sunflower oils for deep frying on their relative densities, the relative densities of each oil sample obtained after each frying cycle of potato and fish were examined, and the obtained results are summarized in Figure 2A and Figure 2B respectively.

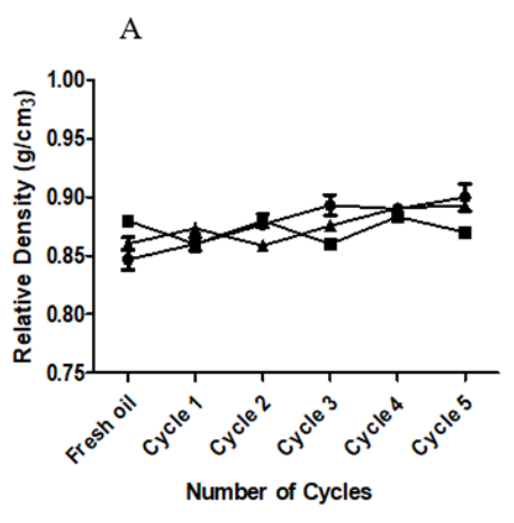

B

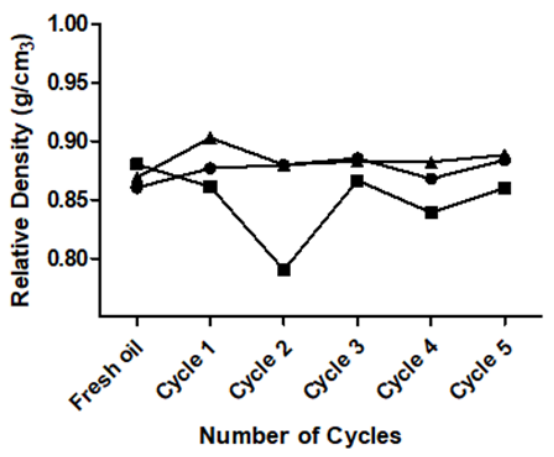

Figure 2. Variation of the Relative Density of coconut oil (Circles), palm oil (Squares) and sunflower oil (Triangles) with repeated frying of potato (A) and fish (B).

Relative densities of all three oil types used in the study were increased slightly with each consecutive frying cycle irrespective of the frying material. However, as shown in Figure $2 \mathrm{~A}$ and Figure 2B, the relative densities of all the tested oils were found to be varied

Table 1. Variation of moisture content of coconut, palm, and sunflower oils during five consecutive frying cycles of potato and fish.

\begin{tabular}{cccccccc}
\hline & Oil type & Fresh & Cycle 1 & Cycle 2 & Cycle 3 & Cycle 4 & Cycle 5 \\
\hline \multirow{4}{*}{ Potato } & Coconut oil & $0.50 \pm 0.17^{\mathrm{c}}$ & $0.25 \pm 0.21^{\mathrm{b}}$ & $0.20 \pm 0.00^{\mathrm{b}}$ & $0.20 \pm 0.00^{\mathrm{b}}$ & $0.03 \pm 0.06^{\mathrm{a}}$ & $0.02 \pm 0.01^{\mathrm{a}}$ \\
& Palm Oil & $0.43 \pm 0.25^{\mathrm{b}}$ & $0.20 \pm 0.00^{\mathrm{a}}$ & $0.40 \pm 0.01^{\mathrm{b}}$ & $0.20 \pm 0.00^{\mathrm{a}}$ & $0.23 \pm 0.09^{\mathrm{a}}$ & $0.23 \pm 0.08^{\mathrm{a}}$ \\
& Sunflower Oil & $0.23 \pm 0.15^{\mathrm{a}}$ & $0.14 \pm 0.02^{\mathrm{a}}$ & $0.15 \pm 0.03^{\mathrm{a}}$ & $0.13 \pm 0.01^{\mathrm{a}}$ & $0.18 \pm 0.07^{\mathrm{a}}$ & $0.14 \pm 0.04^{\mathrm{a}}$ \\
\hline \multirow{4}{*}{ Fish } & Coconut oil & $0.50 \pm 0.17^{\mathrm{a}}$ & $0.87 \pm 0.11^{\mathrm{b}}$ & $0.17 \pm 0.00^{\mathrm{a}}$ & $0.29 \pm 0.16^{\mathrm{a}}$ & $0.86 \pm 0.07^{\mathrm{b}}$ & $1.04 \pm 0.016^{\mathrm{b}}$ \\
& Palm Oil & $0.56 \pm 0.02^{\mathrm{b}}$ & $0.51 \pm 0.18^{\mathrm{ab}}$ & $0.30 \pm 0.00^{\mathrm{ab}}$ & $0.33 \pm 0.19^{\mathrm{ab}}$ & $0.36 \pm 0.21^{\mathrm{ab}}$ & $0.21 \pm 0.1^{\mathrm{a}}$ \\
& Sunflower Oil & $0.23 \pm 0.15^{\mathrm{ab}}$ & $0.17 \pm 0.11^{\mathrm{ab}}$ & $0.16 \pm 0.03^{\mathrm{ab}}$ & $0.41 \pm 0.13^{\mathrm{b}}$ & $0.17 \pm 0.01^{\mathrm{ab}}$ & $0.14 \pm 0.02^{\mathrm{a}}$ \\
\hline
\end{tabular}

Values sharing the same superscript in the same row are not significantly different at $\mathrm{p}<0.05$ Tukey's, HSD post hoc test. All the values are the means of three determinations. 
within the range of 0.85-0.99 throughout the frying process. During frying and heating of oil, hydrolysis, oxidation, polymerization, and isomerization occurs, and those reactions may lead to the formation of different types of polymers which leads to the increase in the density of the frying oil with consecutive frying cycles. According to the results shown in Figure 2, the increase in relative density in palm oil was found to be greater than those of coconut and sunflower oils. As it was reported by Nayak et al. (2015), that the change in density of palm oil with repeated frying was greater than that of olive oil. They have further reported that the change was more prominent after the $20^{\text {th }}$ frying cycle. Moreover, the authors have reported that a higher change in density as a result of the production of higher polymer content in the reuse of palm oil. Relative densities of all three oil types used in the study were increased slightly with each consecutive frying cycle irrespective of the frying material. Accordingly, when compared to coconut and sunflower oil the significant increase in the density of palm oil in the current study was also due to the production of higher polymer content. However, a study by Zahir et al. (2017) confirmed that the density of corn and mustard oil was found to decrease when using the same oil for frying potato for three consecutive frying cycles.

\subsection{Variation of colour of oil during repeated frying}

Colour is considered to be a good visual indicator to determine the quality of frying oil. Thus, the variation of lightness $\left(\mathrm{L}^{*}\right)$, redness $\left(\mathrm{a}^{*}\right)$ and yellowness $\left(\mathrm{b}^{*}\right)$ of all three oil types during reusing of each frying cycle was measured, and the colour difference $(\Delta \mathrm{E})$ value which denotes the tolerance value that defines the acceptable sphere around the standard was calculated. The obtained results are summarized in Table 2 . As per the results, the colour of all the tested oil was found to be darkened during the reuse for frying either potato or fish. As it was explained in the literature, the lower the $\Delta \mathrm{E}$ value, the sample is closer to the standard or the original sample. In consonance with the results in Table 2, darkening of oil was found to be significantly higher in fish fried oil might be due to a comparatively higher level of movement of pigments from fish to the frying oil. Moreover, when compared with the other two types of oil, palm oil showed a higher level of darkening when using fish. According to Nayak et al. (2015), colour changes in palm olein during the deep-frying process was comparatively quicker than that of other oil types.

During deep frying, the darkening of the oil colour occurs due to the formation of pigments such as nonvolatile decomposition products and $\alpha-\beta$ - carbonyl compounds produced through oxidation and decomposition of fatty acids (Nayak et al., 2015). Furthermore, the darkening of oil colour can be also due to caramelized scorched products which accelerate the reduction of L-value in oil. However, in the current study, lightness $\left(\mathrm{L}^{*}\right)$, redness $\left(\mathrm{a}^{*}\right)$, and yellowness $\left(\mathrm{b}^{*}\right)$ of all three oil types were found to be increased with consecutive frying cycles irrespective of the frying material (data not shown). It was also found that the used oil samples were darker, reddish, and yellowish when compared to the colour of the fresh oil. Other than the aforementioned factors, the darkening of the frying oil could be due to the release of brown colour pigments from the frying material into frying oil. Nayak et al.

Table 2. Variation of colour of coconut, palm, and sunflower oils during five consecutive frying cycles of potato and fish

\begin{tabular}{cccccc}
\hline Sample ID & H1-H2 & deltae*ab & Sample ID & H1-H2 & deltae*ab \\
\hline CO PURE & 0.00 & 0.00 & CO PURE & 0.00 & 0.00 \\
COP1 & -13.33 & 5.32 & COF1 & -7.73 & 6.66 \\
COP2 & -3.17 & 4.80 & COF2 & -2.90 & 10.12 \\
COP3 & -2.37 & 4.69 & COF3 & -11.43 & 9.48 \\
COP4 & 5.33 & 6.51 & COF4 & -10.40 & 17.59 \\
COP5 & -1.63 & 6.04 & COF5 & -20.73 & 14.78 \\
POPURE & 0.00 & 0.00 & POPURE & 0.00 & 0.00 \\
POP1 & -0.83 & 1.29 & POF1 & 1.20 & 2.61 \\
POP2 & 4.50 & 3.20 & POF2 & -12.97 & 5.85 \\
POP3 & -4.73 & 2.85 & POF3 & -25.30 & 11.86 \\
POP4 & -7.13 & 2.97 & POF4 & -29.00 & 14.84 \\
POP5 & 2.53 & 2.73 & POF5 & -44.53 & 20.09 \\
SOPURE & 0.00 & 0.00 & SOPURE & 0.00 & 0.00 \\
SOP1 & -8.33 & 2.29 & SOF1 & 5.20 & 8.43 \\
SOP2 & 12.10 & 7.28 & SOF2 & 9.50 & 13.93 \\
SOP3 & 12.27 & 6.45 & SOF3 & 0.50 & 13.55 \\
SOP4 & 5.57 & 6.25 & SOF4 & -9.87 & 14.68 \\
SOP5 & 11.97 & 6.95 & SOF5 & -19.93 & 16.11
\end{tabular}

COP: potato fried in coconut oil, POP: potato fried in palm oil, SOP: potato fried in sunflower oil, COF: fish fried in coconut oil, POF: fish fried in palm oil, SOF: fish fried in sunflower oil. 
(2015) have further reported that the colour of vegetable oil increases with the increase in the frying time. It was also confirmed that the higher the linoleic acid content of the oil, the darker the fried oil.

\subsection{Variation in peroxide value of oils during repeated frying}

The peroxide value is a sound measure of rancidity reactions that occurs in oil throughout storage, which could be ultimately used as a sign of the quality and constancy of fats and oils. This is related to observing the formation of peroxides during the early stages of oxidation. Moreover, the peroxide value was found to be increased with the storage time, temperature, and level of contact with air. Thus, the variation of peroxide value of coconut oil, palm oil and sunflower oil used for deep frying of potato and fish for five consecutive frying cycles were examined, and the obtained results are shown in Table 3.

The results reveal that the PV of coconut oil, palm oil and sunflower oil were increased from 5.76 to 20.42 $\mathrm{meq} / \mathrm{kg}, 7.01-26.79 \mathrm{meq} / \mathrm{kg}$ and $6.05-43.83 \mathrm{meq} / \mathrm{kg}$ respectively after potato was fried (Table 3 ). Recommended limits of peroxide values for quality edible oil are, less than $3 \mathrm{meq} / \mathrm{kg}$ when the oil leaves the processing plant, less than $5 \mathrm{meq} / \mathrm{kg}$ after the bottles are open, and less than $10 \mathrm{meq} / \mathrm{kg}$ in use. Thus, values higher than $10 \mathrm{meq} / \mathrm{kg}$ indicate that the oil is not suitable for cooking purposes (Sebastian et al., 2014). However, according to the obtained results, the peroxide value of all three oil types was found to be slightly higher than the standard value of $5 \mathrm{meq} / \mathrm{kg}$, which could be due to improper storage and packaging that leads to the degradation of fatty acids by photo-oxidation.

According to the results obtained the peroxide value of all three oil types used in the current study were found to be increased with the increase in the number of frying cycles, while the increment is significantly high when using potato as the frying material. The observed increase in the peroxide value is in accordance with the work reported by Omara et al. (2019), Acquah et al. (2016) and $\mathrm{Xu}$ et al. (2015). As per the results obtained in the current study, coconut oil can be used for three consecutive fryings when using potato as the frying material while it has been increased up to four with fish is used as the frying material. In contrast, sunflower oil which is rich in unsaturated fatty acids proven to be used only for two frying cycles with potato and just once with fish. This might be due to the loss of stability of polyunsaturated fatty acids at higher temperatures and easily reacting with oxygen to form peroxides(Serjouie et al., 2010). According to Choe and Ming (2006), the variation of peroxide value is been affected by the amount of unsaturation of the fatty acids present in the oil, storage conditions, exposure to light and temperature, presence of metals and other compounds that accelerates the oxidation of lipids. Moreover, a large number of volatile and non-volatile compounds are generated during the frying process which induced lipid oxidation. However, the produced non-volatile products will be persisted in the food or oil which forms free radicals and badly affect the physical properties of the frying oil. During the frying process, the hightemperature conditions and presence of air and moisture will cause oxidative degradation of fatty acids. Through this process, the lipids present in the oil will partially convert into volatile chain products, different types of polymers and cyclic substances, and non-volatile derivatives and dimers. Production of such volatile and non-volatile products during frying will leads to the development of toxic or carcinogenic compounds that will badly affect the health of the consumers. Consequently, this could be the main reason for the increase in the peroxide value with the increase in the number of frying cycles.

Autoxidation is the principal mechanism of lipid peroxidation. Due to the exposure to high-temperature hydroperoxides are unstable and intermediate and rapidly break down into free radical to initiate autoxidation in addition to other factors such as ionizing radiation, free radicals, photo ion agents and chemicals. According to

Table 3. Variation of peroxide value of coconut, palm and sunflower oils during five consecutive frying cycles of potato and fish.

\begin{tabular}{cccccccc}
\hline & Oil type & Fresh & Cycle 1 & Cycle 2 & Cycle 3 & Cycle 4 & Cycle 5 \\
\hline \multirow{3}{*}{ Potato } & Coconut oil & $5.30 \pm 0.68^{\mathrm{a}}$ & $5.76 \pm 0.01^{\mathrm{b}}$ & $6.15 \pm 0.26^{\mathrm{b}}$ & $9.61 \pm 0.73^{\mathrm{c}}$ & $18.48 \pm 0.79^{\mathrm{d}}$ & $20.42 \pm 0.82^{\mathrm{e}}$ \\
& Palm Oil & $7.01 \pm 0.27^{\mathrm{a}}$ & $7.76 \pm 0.46^{\mathrm{a}}$ & $15.78 \pm 0.31^{\mathrm{b}}$ & $19.57^{\mathrm{c}} \pm 0.49^{\mathrm{c}}$ & $18.50 \pm 0^{\mathrm{d}}$ & $26.79 \pm 0.25^{\mathrm{e}}$ \\
& Sunflower Oil & $6.05 \pm 0.27^{\mathrm{a}}$ & $4.87 \pm 0.23^{\mathrm{a}}$ & $22.59 \pm 1.15^{\mathrm{b}}$ & $33.33^{\mathrm{c}} \pm 0.56^{\mathrm{c}}$ & $41.43 \pm 0.03^{\mathrm{d}}$ & $43.83 \pm 0.64^{\mathrm{e}}$ \\
\hline \multirow{3}{*}{ Fish } & Coconut oil & $5.30 \pm 0.53^{\mathrm{a}}$ & $6.94 \pm 1.74^{\mathrm{ab}}$ & $6.92 \pm 1.22^{\mathrm{ab}}$ & $8.30 \pm 0.74^{\mathrm{b}}$ & $8.64 \pm 0.31^{\mathrm{b}}$ & $9.50 \pm 0.87^{\mathrm{b}}$ \\
& Palm Oil & $7.01 \pm 0.27^{\mathrm{b}}$ & $7.87 \pm 0.23^{\mathrm{bc}}$ & $8.74 \pm 1.15^{\mathrm{c}}$ & $4.28 \pm 0.56^{\mathrm{a}}$ & $4.87 \pm 0.03^{\mathrm{a}}$ & $4.11 \pm 0.64^{\mathrm{a}}$ \\
& Sunflower Oil & $6.05 \pm 0.3^{\mathrm{a}}$ & $13.48 \pm 0.04^{\mathrm{b}}$ & $15.91 \pm 0.79^{\mathrm{c}}$ & $13.22 \pm 0.56^{\mathrm{b}}$ & $5.75 \pm 1.08^{\mathrm{a}}$ & $6.23 \pm 0.61^{\mathrm{a}}$ \\
\hline
\end{tabular}

Values sharing the same superscript in the same row are not significantly different at $\mathrm{p}<0.05$ Tukey's, HSD post hoc test. All the values are the means of three determinations. 
the literature, autoxidation is a three-phase process that involves initiating propagation and termination. The other pathway for lipid peroxidation is hydrolysis. Consequently, the activated molecules break down the esterified bond of triacylglycerides to generate glycerol, free fatty acids monocyglyceride and diacyglycerides. Simultaneously, high temperature persuades polymerization of hydrolysis product and form high molecular weight cyclic fatty acid monomer and diamer (Leong et al., 2015).

Hydro peroxides developed from triacylglycerol are primary oxidation products that may later break into lower molecular weight products such as alcohols, fatty acids, aldehydes, and ketones. These decomposed products can lead to the rancidity of oil in a later stage. Moreover, oxidation of fats and oils that happened during storage or due to heat generated during frying will also contribute to bad flavour and odour of oil. In addition, it will produce different toxic compounds that badly affect health. Thus, the peroxide value of the used oils has been measured for five consecutive frying cycles in the present study.

Peroxides are unstable and could be easily decomposed during the frying process. Furthermore, they can be easily reacting with any antioxidants that could be present in the frying material. Thus, the significantly low level of increase in peroxide value during deep frying of fish could be resulted due to some antioxidant activity that was created by the movement of any antioxidant that was present in the fish.

\subsection{Variation in acid value of oils during repeated frying}

The acid value is the number of milligrams of $\mathrm{KOH}$ that is required to neutralize free fatty acids that is available in one gram of oil, and thus gives an idea about the acidity of oil during frying. Furthermore, the acid value is an indicator of the rancidity of oil or fat. Thus, it would give an idea about the quality and the reusability of oil for deep frying. In this context, during the current study acid value of all three oil using potato and fish as the frying material and the obtained results were summarised in Table 4.
According to the standards set by the Codex Alimentarius Commission, the acid value of refined oil suitable for human consumption is $0.6 \mathrm{mg} \mathrm{KOH} / \mathrm{kg}$ (Wolke, 2007).

The results show that the acid value of coconut oil, palm oil and sunflower oil were increased from 0.465 to $1 \mathrm{mg} \mathrm{KOH} / \mathrm{kg}, 0.456$ to $2.9 \mathrm{mg} \mathrm{KOH} / \mathrm{kg}$ and 0.38 to 2.94 $\mathrm{mg} \mathrm{KOH} / \mathrm{kg}$ respectively in potato fried oil. On the other hand, a significant increase in the acid value of all three oil types was observed after each frying cycle when fish was used as the frying material. The increase in the acid value of oil after frying was mainly due to the hydrolysis of triglycerides at higher temperatures in the presence of moisture and air. Due to hydrolysis triacylglycerol forms mono and diacylglycerol, glycerol, and free fatty acids (FFA). The presence of FFAs in the frying medium will damage the stability of oil and fried food. Moreover, when compared with coconut oil and palm oil, a significant increase in the free fatty acid level was observed in the sunflower oil after the first frying cycle irrespective of the frying material. This is mainly due to the fact that the sunflower oil is rich in unsaturated fatty acids which are highly prone to hydrolysis during the presence of moisture and heat, and thus, produce a higher amount of FFAs that leads to an increase in the acid value.

Furthermore, as shown in Table 4, the acid values of all three types of oils were found to increase with the increase in the number of frying cycles. This is mainly due to the production of carbonyl compounds and low molecular weight free fatty acids that were produced due to oxidation and cleavage of double bonds during deep frying. Furthermore, the moisture released from the fried food will accelerate the hydrolysis of triglycerides to form mono and diglycerides, free fatty acids, and glycerol. These results were in accordance with those reported by Acquah et al. (2016) and Debnath et al. (2009).

Moreover, the change in the acid value during deep frying of oil can be varied depending on the type of fried material used. As per the results shown in Table 4, the

Table 4. Variation of acid value of coconut, palm and sunflower oils during five consecutive frying cycles of potato and fish.

\begin{tabular}{cccccccc}
\hline & Oil type & Fresh & Cycle 1 & Cycle 2 & Cycle 3 & Cycle 4 & Cycle 5 \\
\hline \multirow{3}{*}{ Potato } & Coconut oil & $0.465 \pm 0.19^{\mathrm{a}}$ & $0.505 \pm 0.08^{\mathrm{ab}}$ & $0.56 \pm 0.0^{\mathrm{ab}}$ & $0.835 \pm 0.08^{\mathrm{bc}}$ & $0.615 \pm 0.23^{\mathrm{abc}}$ & $1.00 \pm 0.16^{\mathrm{c}}$ \\
& Palm Oil & $0.456 \pm 0.08^{\mathrm{c}}$ & $0.78 \pm 0.0^{\mathrm{a}}$ & $0.95 \pm 0.08^{\mathrm{a}}$ & $1.12 \pm 0.16^{\mathrm{b}}$ & $1.12 \pm 0.0^{\mathrm{b}}$ & $2.90 \pm 0.02^{\mathrm{d}}$ \\
& Sunflower Oil & $0.38 \pm 1.61^{\mathrm{a}}$ & $1.76 \pm 0.02^{\mathrm{b}}$ & $2.56 \pm 0.16^{\mathrm{c}}$ & $2.69 \pm 0.32^{\mathrm{c}}$ & $2.67 \pm 0.35^{\mathrm{c}}$ & $2.94 \pm 0.2^{\mathrm{c}}$ \\
\hline \multirow{2}{*}{ Fish } & Coconut oil & $0.47 \pm 0.19^{\mathrm{a}}$ & $2.46 \pm 0.01^{\mathrm{b}}$ & $2.66 \pm 0.26^{\mathrm{bc}}$ & $3.30 \pm 0.3^{\mathrm{d}}$ & $2.59 \pm 0.15^{\mathrm{bc}}$ & $2.90 \pm 0.02^{\mathrm{cd}}$ \\
& Palm Oil & $0.456 \pm 0.08^{\mathrm{a}}$ & $2.96 \pm 0.59^{\mathrm{b}}$ & $1.90 \pm 0.16^{\mathrm{a}}$ & $2.67 \pm 0.01^{\mathrm{b}}$ & $3.01 \pm 0.12^{\mathrm{b}}$ & $2.99 \pm 0.21^{\mathrm{b}}$ \\
& Sunflower Oil & $0.38 \pm 1.61^{\mathrm{a}}$ & $4.18 \pm 0.16^{\mathrm{d}}$ & $2.79 \pm 0.17^{\mathrm{b}}$ & $2.91 \pm 0.0^{\mathrm{b}}$ & $3.11 \pm 0.28^{\mathrm{bc}}$ & $4.09 \pm 0.44^{\mathrm{cd}}$ \\
\hline
\end{tabular}

Values sharing the same superscript in the same row are not significantly different at $\mathrm{p}<0.05$ Tukey's, HSD post hoc test. All the values are the means of three determinations. 
acid value of all three oil types was found to be increased significantly when fish was used as the frying material. These results were in accordance with Naz et al. (2005) where they observed that the free fatty acid level of oil used for deep frying of chicken drumsticks was higher than that of the oil used for deep frying of potato. This is mainly depending on the moisture content of the product subjected to frying. When compared to the moisture content, salaya fish is having around $82 \%$ of moisture while the potato was around $76 \%$. Higher the initial moisture content in the fried food, higher the amount of water released to the frying medium that leads to an increase in the oxidation and hydrolysis of lipids which eventually increase the acid value of the frying oil. Moreover, as it was reported by Nayak (2015), the acid value of the used oil can be increase when they are used in the frying of food product rich in fat. This was mainly due to the release of fatty acids from the fat-containing food to the frying oil which eventually leads to the increase of the acid value of such oil.

As reported in the Codex Alimentarius Commission (1999), the safe level of acid value in oil for human consumption was found to be $0.6 \mathrm{mg} \mathrm{KOH} / \mathrm{kg}$ oil. Thus, when considering the results obtained, out of the three tested oil types, only coconut oil can be reused only up to two cycles in deep frying of products like a potato. Furthermore, this number of cycles will be reduced with the increase in the moisture content and the fat content in the fried food material.

\subsection{Effect of repeated frying on total phenolic content and the antioxidant content of oil}

In order to determine the effect of repeated frying on the phenolic and antioxidant content of the frying oil, coconut oil after the third frying cycle of potato and fifth frying cycle of fish; palm oil after the first frying of potato and second frying of fish; and sunflower oil after single frying of either potato or fish were used. The results obtained of total phenolic content and the antioxidant activity are summarized in Figure $3 \mathrm{~A}$ and $3 \mathrm{~B}$ respectively.

As shown in Figure 3, when compared to the total phenolic content of fresh oil, the total phenolic content of coconut, palm and sunflower oils after the $5^{\text {th }}, 2^{\text {nd }}$, and $1^{\text {st }}$ frying cycles of fish were found to be increased significantly. But in contrast, the phenolic content of coconut and palm oil used for frying of potato were found to increase slightly while sunflower oil was found to be reduced. These results are in accordance with the findings of both acid value and peroxide values of all three oil types used in the frying of fish. As shown in Table 3, the peroxide value of both coconut and palm oil used in repeated frying of fish was found to be within the standard value set by the Codex Alimentarius Commission (1999). This could be due to the release of phenolic compounds by the frying fish to the oil that controls the chemical reactions leads to an increase in peroxide and acid values of oil.

A
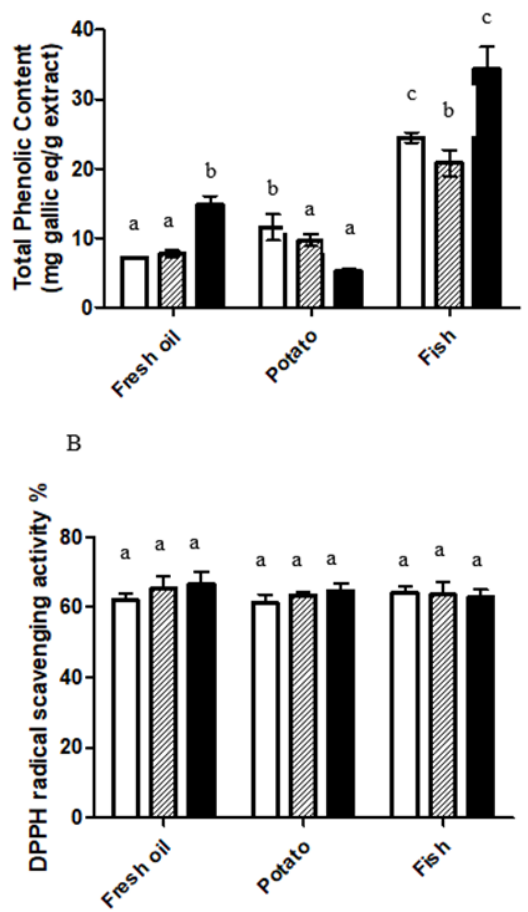

Figure 3. Comparison of the total phenolic contents (A) and total antioxidant activity (B) of coconut oil (white bars) after the third and fifth frying cycles of potato and fish respectively; palm oil (lined bars) after the first and second frying of potato and fish respectively; and sunflower oil (black bars) after the first frying of both potato and fish.

Each bar represent mean of three replicates, and bars indicating the means with same letters in same oil type are not significantly different at $\mathrm{p}<0.05$ in Tukey's HSD, post hoc test.

During the lipid peroxidation, reactive oxygen species (ROS) which are unstable in nature will be formed excessively. Antioxidants present in the cooking oil will scavenge these free radicals and ROS during frying. However repeated heating of oil leads to oxidation and thus, production of rancid odour and flavour. Due to the oxidation process, both the nutritional value and safety of fried food will be reduced. The increase in the concentration of oxidized triacylglycerol monomers, dimers, polymers, and polar compounds in cooking oil during heating will make the oil more susceptible to oxidation following repeated heating. Vitamin E, tocotrienols isomers and tocopherols are the major antioxidants in cooking oil. The constancy of vitamin $\mathrm{E}$ isomers differs during heating because it is determined by the type of cooking oil and the content of vitamin E(Leong et al., 2015). Thus, the effect of heating on the total antioxidant content of the three oil 
types was also examined, and the results are summarized in Figure 3B. As per the results shown in Figure 3B, the percentage inhibition of radical scavenging ability of all three oil types used for repeated frying of potato and fish were not found to be changed significantly from that of fresh oil. However, a slight increase in the DPPH radical scavenging activity of coconut oil used in the frying of fish was found, and this could be due to the presence of high phenolic content in fish.

\section{Conclusion}

According to the results obtained, both coconut oil and palm oil can be used repeatedly for several frying cycles. However, the number of cycles that can be used for repeated frying is varying with the type of food material that has been used for frying, where coconut oil can be used for three frying cycles of potato and five frying cycles of fish: palm oil for one frying of potato and two frying of fish. In contrast, the use of unsaturated oil like sunflower oil on repeated frying is not recommended.

\section{Conflict of interest}

The authors declare no conflict of interest.

\section{Acknowledgement}

The authors wish to acknowledge the Faculty of Agriculture, University of Ruhuna, Sri Lanka for granting the Faculty Research Grant (2019) which has been used as partial funding for the current research study.

\section{References}

Acquah, N.I., Obeng, G.Y. and Mensah, E. (2016). Repetitive use of vegetable oil and effects on physico-chemical properties - Case of frying with redfish (Lutjanus fulgens). Science and Technology, 6(1), 8-14. https://doi.org/10.5923/ j.scit.20160601.02.

Alzaa, D.F., Guillaume, C. and Ravetti, L. (2018). Evaluation of Chemical and Physical Changes in Different Commercial Oils during Heating. Acta Scientific Nutritional Health, 2(6), 2-11. https:// actascientific.com/ASNH/pdf/ASNH-02-0083.pdf.

AOAC (Association of Official Analytical Chemists). (2000). Official methods of analysis. $15^{\text {th }}$ ed., p. 969 -991. Washington, D.C, USA.: AOAC.

Choe, E. and Ming B.D. (2006). Mechanisms and factors for edible oil oxidation. Comprehensive Reviews in Food Science and Food Safety, 5(4), 169-186. https://doi.org/10.1111/j.1541-4337.2006.00009.x
Codex Alimentarius Commission. (1999). Codex Standard for Named Vegetable Oils Codex Stan 2101999. Rome: FAO.

Debnath, S., Rastogi, N., Krishna, A.G. and Lokesh, B.R. (2009). Oil partitioning between surface and structure of deep-fat fried potato slices: A kinetic study. LWT - Food Science and Technology, 42(6), 1054-1058.

https://doi.org/10.1016/

j.lwt.2009.01.006

Eyers, L. (2015) Frying oils: Selection, smoke points and potential deleterious effects for health. Food New Zealand, 15(1), 30-31.

Garrido-Polonio, C., Garcia-Linares, M.C., Garcia-Arias, M.T., Lopez-Varela, S., Garcia-Katragadda, H.R., Fullana, A., Sidhu, S. and Carbonell-Barrachina, A.A. (2009). Emissions of volatile aldehydes from heated cooking oils. Food Chemistry, 120(1), 59-65. https://doi.org/10.1016/j.foodchem.2009.09.070

Hashem, H.A., Shahat, M., El-Behairy, S.A. and Sabry, A. (2017). Use of Palm Olein for Improving the Quality Properties and Oxidative Stability of Some Vegetable Oils during Frying Process. Middle East Journal of Applied Science and Technology, 7(1), 68 -79. http://www.curresweb.com/mejas/index.htmL (ISSN: 2077-4613).

Lapointe, A., Couillard, C. and Lemieux, S. (2006). Effects of dietary factors on oxidation of low-density lipoprotein particles. The Journal of Nutritional Biochemistry, 17(10), 645-58 https:// doi.org/10.1016/j.jnutbio.2006.01.001

Leong, X.F., Aishah, A., Nor Aini, U., Das, S. and Jaarin, K. (2008). Heated palm oil causes rise in blood pressure and cardiac changes in heart muscle in experimental rats. The Archives of Medical Research, 39(6), 567-572. https://doi.org/10.1016/ j.arcmed.2008.04.009

Leong, X.-F., Ng, C.Y., Jaarin, K. and Mustafa, M. (2015). Effects of Repeated Heating of Cooking Oils on Antioxidant Content and Endothelial Function. Austin Journal of Pharmacology and Therapeutics, 3 (2), 1068-1074.

Nayak, P.K., Dash, U., Rayaguru, K. and Krishnan, K.R. (2015). Physio-Chemical Changes During Repeated Frying of Cooked Oil: A Review. Journal of Food Biochemistry, 40(3), 371-390. https:// doi.org/10.1111/jfbc.12215

Naz, S., Siddiqi, R., Sheikh, H. and Sayeed, S.A. (2005). Deterioration of olive, corn, and soybean oils due to air, light, heat and deep frying. Food Research International, 38(2), 127-134. https:// doi.org/10.1016/j.foodres.2004.08.002

Omara, T., Kigenyi, E., Laker, F., Adokorach, M., Otim, 
G., Kalukusu, R., Musau, B., Kagoya, S. and Nakabuye, B.V. (2019). Effects of Continuous Deep Fat Frying on the Physical 3 and Chemical Properties of Assorted Brands of Edible four Cooking Oils Sold in Metropolitan Kampala. Asian Journal of Applied Chemistry Research, 3(2), 1-13. https://doi.org/10.9734/ajacr/2019/v3i230086

Saxena, A. (2014). Re-using cooking oil is a recipe for harmful trans-fats, experts warn. Popular Article, Mail Online.

Sebastian, A., Ghazani, S.M. and Marangoni, A.G. (2014). Quality and safety of frying oils used in restaurants. Food Research International, 64, 420423. https://doi.org/10.1016/j.foodres.2014.07.033

Serjouie, A., Tan, C.P., Mirhosseini, H. and Che Man, Y.B. (2010). Effect of Vegetable-Based Oil Blends on Physicochemical Properties of Oils During DeepFat Frying. American Journal of Food Technology, 5 (5), 310-323. https://doi.org/10.3923/ ajft.2010.310.323

Sülzle, A., Hirche, F. and Eder, K. (2004). Thermally oxidized dietary fat upregulates the expression of target genes of PPAR alpha in rat liver. The Journal of Nutrition, 134(6), 1375-1383. https:// doi.org/10.1093/jn/134.6.1375.

Wang, T. (2002). Soybean oil. In Gunstone, F. (Ed). Vegetable Oils in Food Technology: Composition, Properties and Uses, p. 18-58. UK: Blackwell Publishing Ltd.

Wolke, R.L. (2007). Where There's Smoke, There's a Fryer. The Washington Post.

Xu, T., Li, J., Fan, Y., Zheng, T. and Deng, Z. (2015). Comparison of oxidative stability among edible oils under continuous frying conditions. International Journal of Food Properties, 18(7), 1478-1490. https://doi.org/10.1080/10942912.2014.913181

Zahir, E., Saeed, R., Hameed, M.A. and Yousuf, A. (2017). Study of physicochemical properties of edible oil and evaluation of frying oil quality by Fourier Transform-Infrared (FT-IR) Spectroscopy. Arabian Journal of Chemistry, 10(Supplement 2), 3870-3876. https://doi.org/10.1016/ j.arabjc.2014.05.025 